\title{
Ranibizumab port delivery system (RPDS): realising long awaited dream of prolonged VEGF suppression
}

\author{
Ashish Sharma ${ }^{1}$ - Nilesh Kumar ${ }^{1} \cdot$ Nikulaa Parachuri $^{1}$ - Baruch D Kuppermann ${ }^{2}$ - Francesco Bandello ${ }^{3}$ \\ Carl D. Regillo ${ }^{4}$
}

Received: 5 May 2019 / Accepted: 8 May 2019 / Published online: 5 June 2019

(c) The Royal College of Ophthalmologists 2019

Ranibizumab (Genentech, South San Francisco, CA, USA) was a revolutionary anti-VEGF molecule approved by FDA in 2006 for neovascular age-related macular degeneration (nAMD). It had a paradigm-shifting effect on the treatment of various retinal neovascular pathologies, especially in nAMD and diabetic macular oedema (DME) [1, 2]. Ranibizumab monthly dose regimen has brought down the blindness attributable to nAMD by $72 \%$ and thus has provided a new lease of functional and quality life to the patients [2].

Since the introduction, except for a biosimilar that was approved for the Indian market, there has not been any advancement for the molecule per se [3]. The dosing, the delivery system, and the efficacy and safety have all been stagnant for the last 13 years [1]. In 2016 and 2018, the FDA had approved pre-filled syringes for ranibizumab in $0.5 \mathrm{mg}$ dose and $0.3 \mathrm{mg}$ dose, which was the first improvement in the delivery system since its launch [1]. Multiple trials have provided us with some guidelines such as monthly, pro re nata (PRN) and Treat and Extend (TREX). However, they all have a common denominator of being multiple injections regimen [4-6].

Ranibizumab port delivery system (RPDS) is an implantable, reservoir-based, slow-release platform. It sits in the sclera and delivers ranibizumab in a concentrated solution at different doses in the setting of nAMD. RPDS is

Ashish Sharma

drashish79@hotmail.com

1 Department of Vitreoretina, Lotus Eye Hospital and Institute, Coimbatore, TamilNadu 641014, India

2 Gavin Herbert Eye Institute, University of California, Irvine, Irvine, CA 92697, USA

3 Department of Ophthalmology, Scientific Institute San Raffaele, University Vita-Salute, 20132 Milano, Italy

4 The Retina Service of Wills Eye Hospital, Mid Atlantic Retina, Philadelphia, PA 19107, USA a transforming pharmaceutical innovation to overcome the hurdle of frequent intravitreal injections [7]. Multiple, frequent injections over time carry a higher, cumulative risk of adverse events such as haemorrhage, inflammation, ocular hypertension, and infection, as well as an increased financial burden on the patients [8]. It also leads to poor patient compliance in long-term therapy and loss of the initial visual gains over time in many patients based on real-world utlization study outcomes. RPDS provides an opportunity to have an implant introduced into the vitreal cavity by a surgical procedure and refill of that implant as an officebased procedure. Recently Phase 2 results of the RPDS were revealed by Genentech and were termed the LADDER (Long Acting Delivery of Ranibizumab) trial [7]. This trial showed a promising outcome for the implant. The trial comprised of 4 arms being evaluated; namely RPDS $10 \mathrm{mg} / \mathrm{ml}, \quad 40 \mathrm{mg} / \mathrm{ml}, \quad 100 \mathrm{mg} / \mathrm{ml}$, and monthly $0.5 \mathrm{mg}$ injections. Two hundred and thirty two ranibizumabresponsive patients with nAMD were recruited in the study, and data from 220 patients was considered for analysis. The RPDS implant was filled with $0.02 \mathrm{ml}$ of a customised formulation of ranibizumab in varying concentrations. This formulation is different from the FDA approved formulation used in the monthly injection regimen [9]. The refill time was determined by a set protocol that included subjective and objective end points. The results demonstrated that $100 \mathrm{mg} / \mathrm{ml}$ RPDS had a similar visual outcome to monthly ranibizumab injections. It had a mean refill time of 15 months, with $80 \%$ of the patients not requiring a refill per protocol for the first 6 months. There was no significant difference between the mean refill time of $40 \mathrm{mg} / \mathrm{ml}$ and $100 \mathrm{mg} / \mathrm{ml}$ arm but $100 \mathrm{mg} / \mathrm{ml}$ had a better visual outcome [7]. The promising results have led to the Phase $3 \mathrm{ARCH}-$ WAY trial [10]. It is a multicenter, randomised, open-label study comparing safety, efficacy, and pharmacokinetics of $100 \mathrm{mg} / \mathrm{ml}$ solution for RPDS with $0.5 \mathrm{mg}(10 \mathrm{mg} / \mathrm{ml})$ solution of ranibizumab for intravitreal injections, and is expected to be completed by May 2022. In tandem, 
Genentech has also initiated the long-term efficacy and safety trial for the RPDS, which includes patients who successfully participated in the LADDER and ARCHWAY trials. Dubbed as PORTAL trial, it will evaluate 500 participants for 144 weeks with 24 weeks periodic refill of $100 \mathrm{mg} / \mathrm{ml}$ formulation for various outcomes. The trial is expected to be completed by June 2022 [11].

To realise the goal of long-term VEGF suppression, RPDS has gone through various stages and modification, such as laser photocoagulation of pars plana uvea at the scleral incision used to insert the device. It has significantly made the procedure safer by bringing down the rate of postoperative vitreous haemorrhage. The implantation procedure allows for the device to be secured in a well-tolerated, self-retaining, sutureless fashion, and the office-based refill approach performed on an infrequent basis makes it attractive for widespread clinical use in the future [7].

RPDS is poised to provide relief to patients who do not want to undergo frequent anti-VEGF injections. In addition, it may help to minimise the relative undertreatment that occurs in the real-world setting and better maintain vision gains over time in patients with nAMD [12]. Clinicians are looking forward to the results of the phase III ARCHWAY clinical trial. If this deliver system is successful in the treatment of patients with nAMD, it could also transform the other diseases with injection burden such as macular oedema related to diabetic retinopathy and retinal vein occlusion. RPDS is the first successful step towards attaining a truly long-acting antiVEGF delivery. It will help pave the way for other strategies of long-term VEGF suppression such as injectable biodegradable polymer implants, drug encapsulation in injectable liposomes, microparticles and nanoparticles.

\section{Compliance with ethical standards}

Conflict of interest The authors declare that they have no conflict of interest.

Publisher's note Springer Nature remains neutral with regard to jurisdictional claims in published maps and institutional affiliations.

\section{References}

1. Lucentis (ranibizumab) FDA approval history. Drugs.com. https://www.drugs.com/history/lucentis.html. Accessed $27 \mathrm{Apr}$ 2019.

2. Mitchell P, Bressler N, Doan QV, Dolan C, Ferreira A, Osborne A, et al. Estimated cases of blindness and visual impairment from neovascular age-related macular degeneration avoided in australia by ranibizumab treatment. PLoS ONE. 2014;9:e101072.

3. Sharma A, Reddy P, Kuppermann BD, Bandello F, Loewenstein A. Biosimilars in ophthalmology: Is there a big change on the horizon? Clin Ophthalmol. 2018;12:2137-43.

4. Rufai SR, Almuhtaseb H, Paul RM, Stuart BL, Kendrick T, Lee $\mathrm{H}$, et al. A systematic review to assess the 'treat-and-extend' dosing regimen for neovascular age-related macular degeneration using ranibizumab. Eye. 2017;31:1337-44.

5. Chin-Yee D, Eck T, Fowler S, Hardi A, Apte RS. A systematic review of as needed versus treat and extend ranibizumab or bevacizumab treatment regimens for neovascular age-related macular degeneration. Br J Ophthalmol. 2016;100:914-7.

6. Silva R, Berta A, Larsen M, Macfadden W, Feller C, Monés J. Treat-and-extend versus monthly regimen in neovascular age-related macular degeneration. Ophthalmology. 2018; 125:57-65.

7. Campochiaro PA, Marcus DM, Awh CC, Regillo C, Adamis AP, Bantseev $\mathrm{V}$, et al. The port delivery system with ranibizumab for neovascular age-related macular degeneration: results from the randomized phase 2 ladder clinical trial. Ophthalmology. 2019. https://doi.org/10.1016/j.ophtha.2019.03.036.

8. Boyle J, Vukicevic M, Koklanis K, Itsiopoulos C, Rees G. Experiences of patients undergoing repeated intravitreal anti-vascular endothelial growth factor injections for neovascular age-related macular degeneration. Psychol Health Med. 2018;23:127-40.

9. Genentech: Press Releases/Wednesday, Jul 25, 2018. https://www. gene.com/media/press-releases/14739/2018-07-25/genentechunveils-positive-phase-ii-resu. Accessed 27 Apr 2019.

10. A Phase III study to evaluate the port delivery system implant with ranibizumab compared with monthly ranibizumab injections in participants with wet age-related macular degeneration (Archway). ClinicalTrials.gov. https://clinicaltrials.gov/ct2/show/ NCT03677934. Accessed 26 Apr 2019.

11. Extension study for the port delivery system with ranibizumab (Portal) ClinicalTrials.gov. https://clinicaltrials.gov/ct2/show/ NCT03683251. Accessed 27 Apr 2019.

12. Loewenstein A. Breaking the burden: a new way to deliver antiVEGF. https://www.reviewofoptometry.com/article/breaking-theburden-a-new-way-to-deliver-antivegf. Accessed 27 Apr 2019. 